

\section{Nubosidad variable - Partially cloudy}

\section{Timoteo Marchini}

El Gato y La Caja

Buenos Aires, Argentina

llustradora: Pupé

Fecha de publicación: 12/5/20

Link a la nota original: https://beta.elgatoylacaja.com/nubosidad-variable

\section{Abstract}

Lockdown measures to fight the COVID-19 pandemic led to a secondary improvement in the air quality of major cities worldwide. Decreased mobility and slowing down of industrial and economic activity explain most of this effect. Unfortunately, when easing measures were implemented, air quality rapidly dropped to the levels observed before the lockdown. Moreover, no significant benefit has been evidenced in current Global Warming and Climate Change. In this article, originally published in El Gato y La Caja, Timoteo Marchini presents how the COVID-19 pandemic has highlighted the need of humans to establish a healthy relationship with the environment, not only for our development but for our survival. 
La presión que ejercemos los seres humanos sobre el ambiente en el que nos desarrollamos para hacer nuestras cosas de humanos, más que unidireccional y definitiva, es un ida y vuelta. Invertimos tiempo y energía en expandir a nuestra especie lo más posible, pero cuando dejamos de hacerlo tan activamente, el ambiente contraataca con fuerza para reclamar lo que siempre fue suyo. Es un (des)equilibrio altamente dinámico. Una constante batalla en la difusa frontera que divide a la humanidad de la naturaleza, trazando un límite más frágil de lo que nuestro pensamiento antropocéntrico muchas veces nos permite concebir. Como cuando en el medio de la ciudad una casa es abandonada y poco a poco le crece el pasto y se llena de gatitos, el ambiente retoma posiciones cuando bajamos la guardia.

Por eso, desde que distintos países comenzaron a tomar medidas de aislamiento social y restricción de la movilidad para frenar el avance del nuevo coronavirus, se han observando tremendas mejoras en la calidad del aire, sobre todo en las grandes ciudades. De forma indirecta, esto está contribuyendo a prevenir que un gran número de personas enfermen y mueran por respirar, constantemente y sin sospecharlo, niveles peligrosos de contaminantes ambientales.

Pero claro, las cosas nunca son sencillas. No basta con alegrarse porque nuestro esfuerzo por respetar el aislamiento esté teniendo también un impacto positivo en el ambiente. Esta nueva realidad está desnudando intentos no tan sutiles de manipular la información que va apareciendo, de forma tal de que algunos grupos puedan llevar agua para su molino. Y aún más: esta pandemia puso en evidencia ante los ojos de muchísimas personas la fragilidad de los modelos económicos actuales y las desigualdades que sufrimos quienes formamos parte de ellos.

Esto es, entonces, un problema multifacético. Vamos a intentar echar algo de luz al respecto.

\section{Los datos}

Poco después de que el coronavirus fue declarado pandemia, la Agencia Espacial Europea comenzó a difundir imágenes obtenidas por su satélite Copérnico Sentinel-5P que muestran la calidad del aire en distintas zonas alrededor del mundo, antes y después de entrar en cuarentena. Estos datos corresponden a los niveles de dióxido de nitrógeno (NO2), un gas altamente tóxico que se emite principalmente por el transporte y algunas actividades industriales, y que produce un importante daño en los pulmones cuando lo inhalamos, lo que favorece la aparición de enfermedades respiratorias y disminuye nuestra capacidad de 
respuesta frente a infecciones. Pero ¿qué significan verdaderamente estos datos? ¿Cuál es el impacto real de estos cambios sobre el ambiente y la salud de las personas? ¿Tiene sentido que entremos en cuarentena por un par de semanas cada año para limpiar el aire de nuestras ciudades?

\section{https://www.youtube.com/watch?v=6DWBhp-oKOI\&feature=emb logo}

Cambios en los niveles de NO2 en China y alrededores por la entrada en cuarentena para frenar la propagación del coronavirus.

El primer lugar donde se observaron disminuciones en los niveles de NO2 fue en China, lo cual tiene sentido, al ser los primeros en declarar zonas en cuarentena para frenar el avance del virus. Un aspecto no menor de estos datos es que la cuarentena en la ciudad de Wuhan, donde empezó todo este lío, se dictó el jueves 23 de enero, justo dos días antes del Año Nuevo Lunar Chino, una época en la que todos los años se registran este tipo de disminuciones en los niveles de contaminación ambiental por el cese de actividades asociado a las celebraciones. Como no podemos diferenciarlo del 'efecto Año Nuevo', no tiene demasiado valor analizar los datos antes y después de la cuarentena. Es mejor compararlos con el mismo período del año anterior. Recién ahí se puede ver que, si bien en ambos casos los niveles de NO2 disminuyen hacia fines de enero, en el 2019 estos valores vuelven a aumentar a principios de febrero, cuando las principales ciudades retomaron su ritmo habitual. Por el contrario, los valores de NO2 en el 2020 fueron entre un $20 \%$ y un $30 \%$ más bajos, probablemente por la disminución de la movilidad y una caída del consumo de combustibles fósiles asociados a la cuarentena.

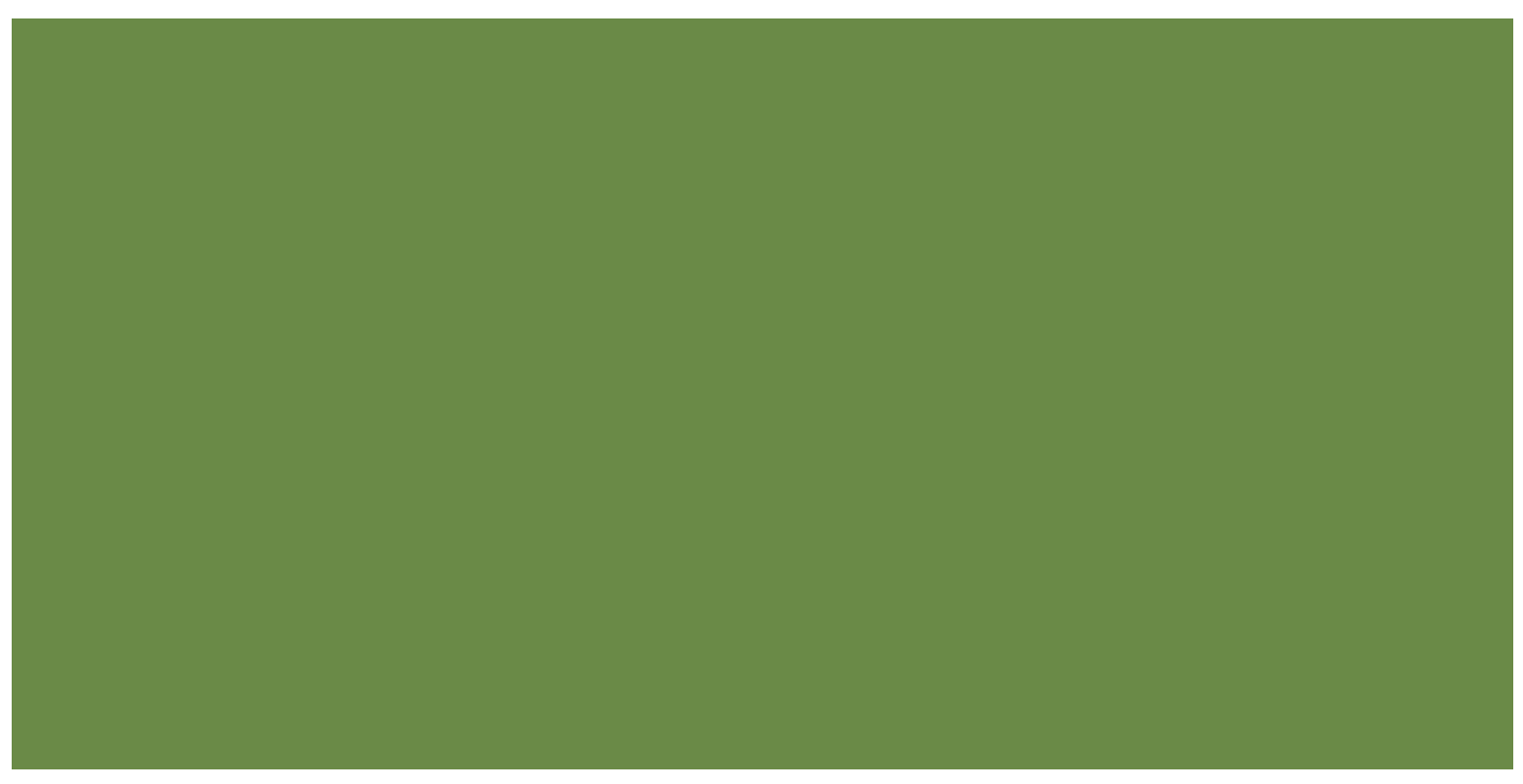


Niveles de NO2 (nubes amarillentas) en el este de China, la península de Corea, y la isla de Japón. A la fecha, el COVID-19 ha matado a unas 5500 personas en esta parte del mundo. Según la Organización Mundial de la Salud (OMS), la contaminación ambiental produce unos 2 millones de muertes cada año en esta zona.

Es notable lo rápido que disminuyen (y vuelven a aumentar) los niveles de NO2 según haya más o menos movilidad y actividad industrial. Resulta que este contaminante se produce, principalmente, por una reacción química entre el oxígeno y el nitrógeno del aire, que ocurre en las condiciones totalmente artificiales de alta presión y temperatura que hay dentro de los motores. Los catalizadores de los autos bloquean la emisión de gran parte de este gas, pero algo siempre se escapa. Una vez liberado a la atmósfera, el NO2 se descompone más rápidamente cuanta más humedad haya en el ambiente, y si hay algo de luz solar que lo ayude a reaccionar para formar otros contaminantes secundarios, más todavía. Esto explica que en áreas urbanas haya grandes variaciones en los niveles de NO2 según el clima, las distintas horas del día (con máximos durante las horas pico, cuando todos vamos para el mismo lugar en el mismo momento), o el día de la semana (por la menor circulación de autos durante el fin de semana).

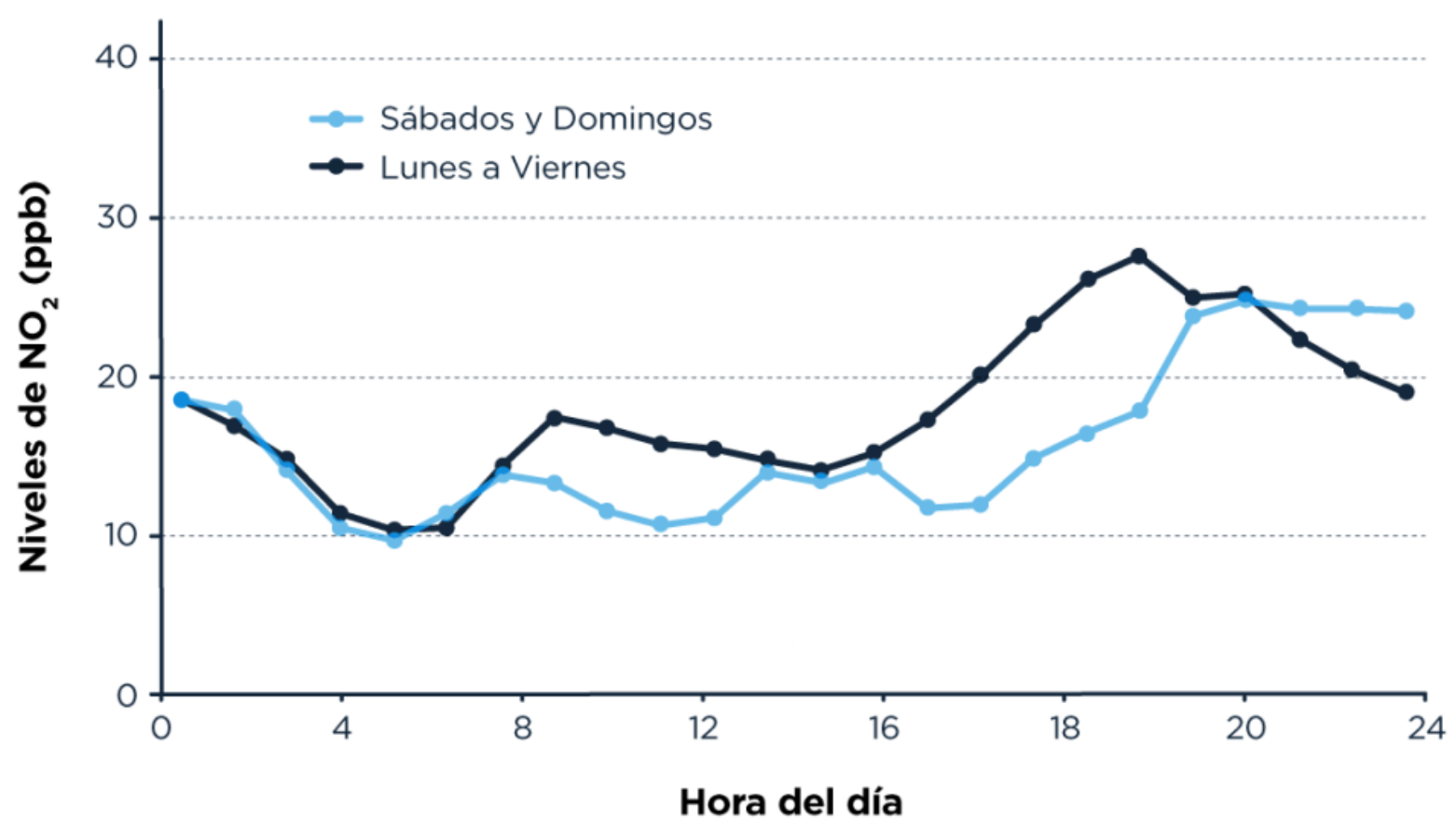


Niveles de NO2 en la Ciudad de Buenos Aires en distintos momentos del día, durante la semana o el fin de semana, antes de que se implementara la cuarentena. Aquellos días felices en los que el aislamiento social era algo que pasaba en otros continentes.

Estos cambios rápidos en los niveles de NO2 asociados al uso del transporte quieren decir que, lamentablemente, la calidad del aire de las grandes ciudades va a volver a empeorar a las pocas horas de que se levante la cuarentena.

\section{Cuarentena, contaminación ambiental y posverdad}

La concentración de NO2 en el aire también disminuyó notablemente en el norte de Italia y el resto de Europa. Los datos más actualizados estiman una reducción de entre el 47\% (Milán) y el 54\% (París) en esta zona. Algo similar ocurrió en los Estados Unidos, la India, e incluso en las principales ciudades de nuestro país. 
Journal of Science, Humanities and Arts

\section{Buenos Aires}

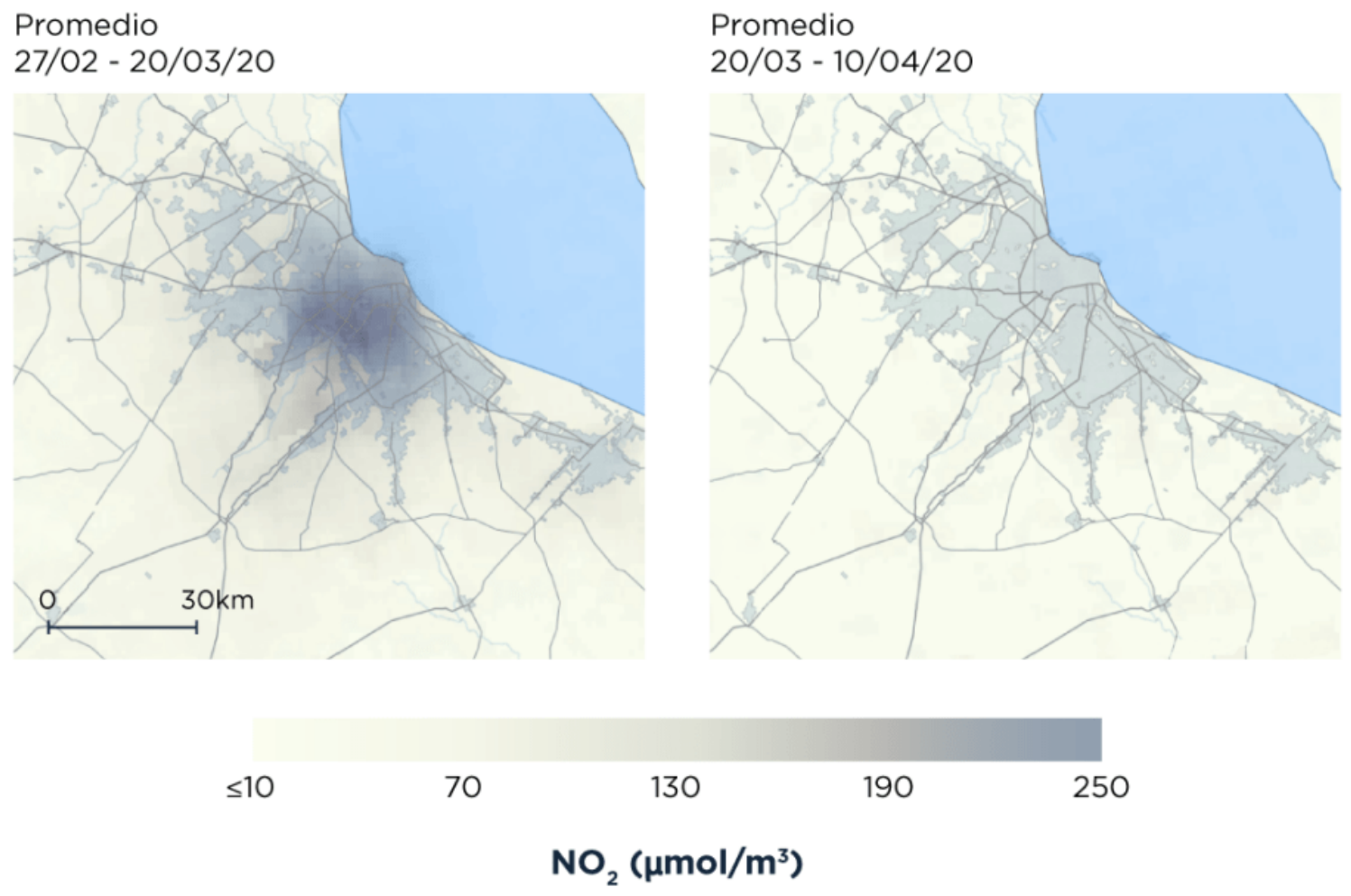




\section{Rosario}

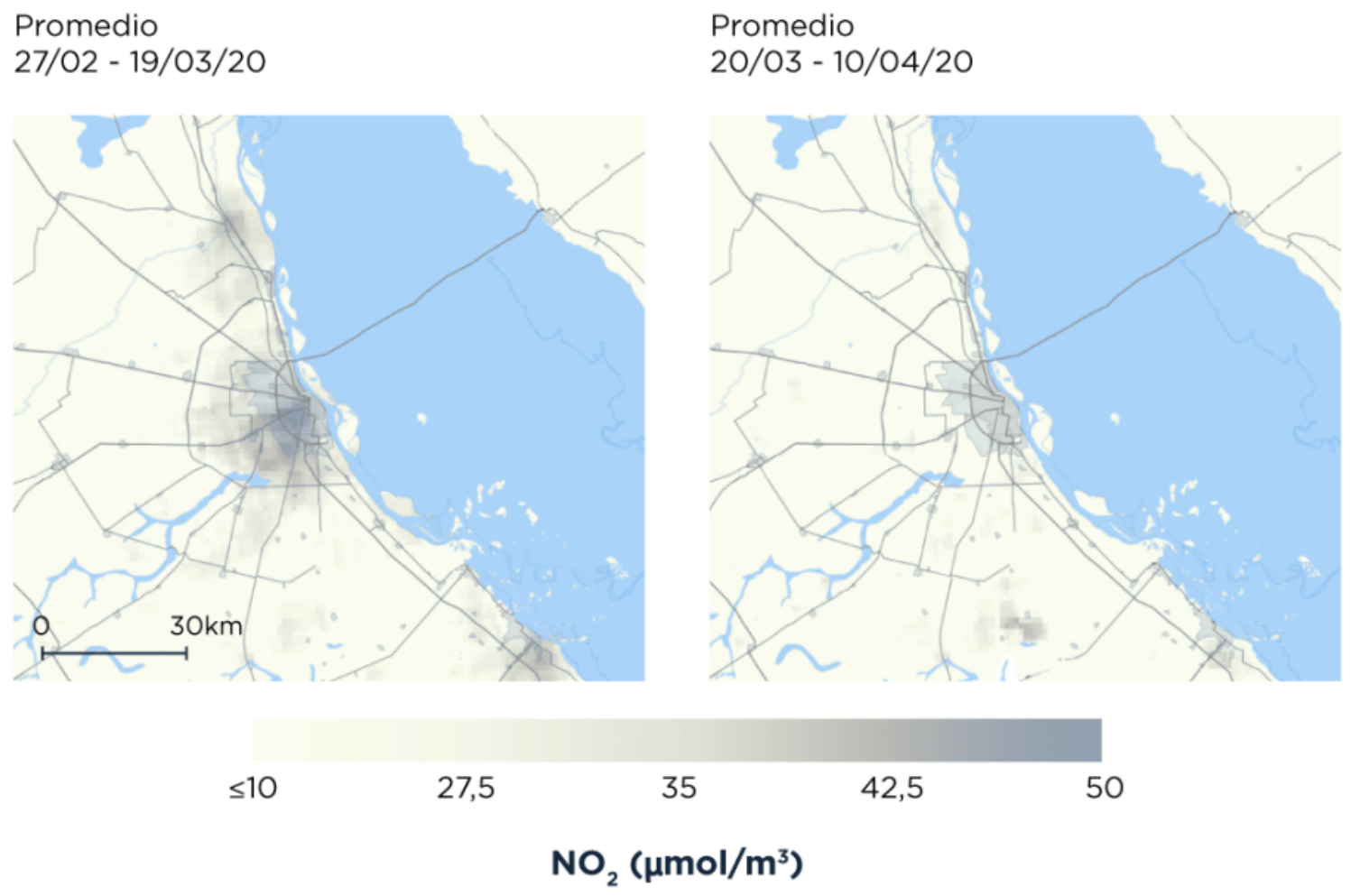



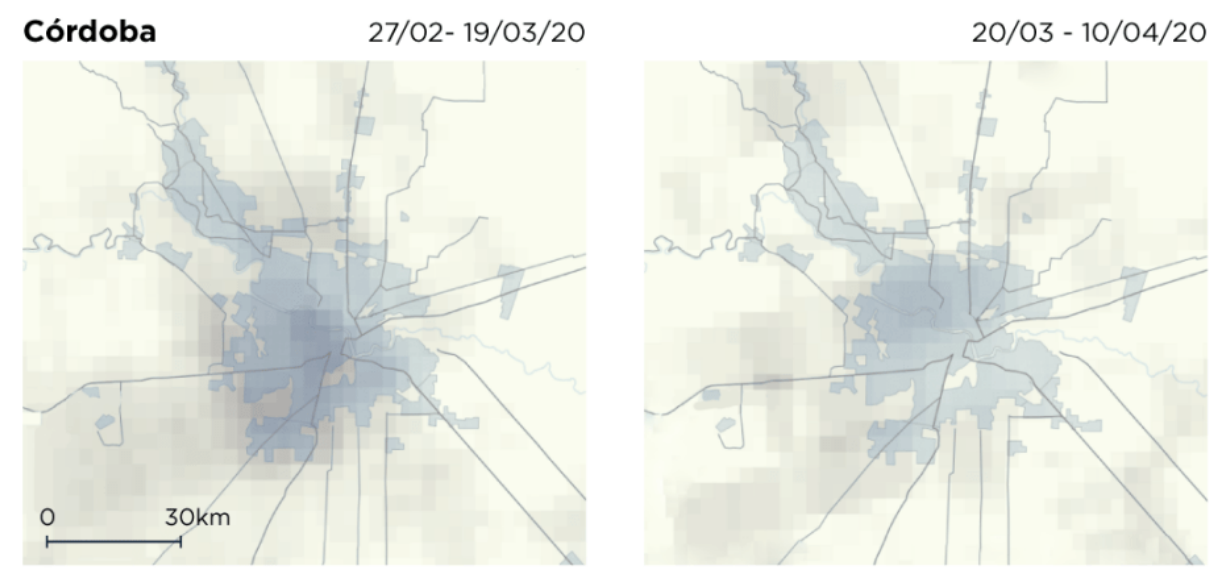

\section{Mendoza}
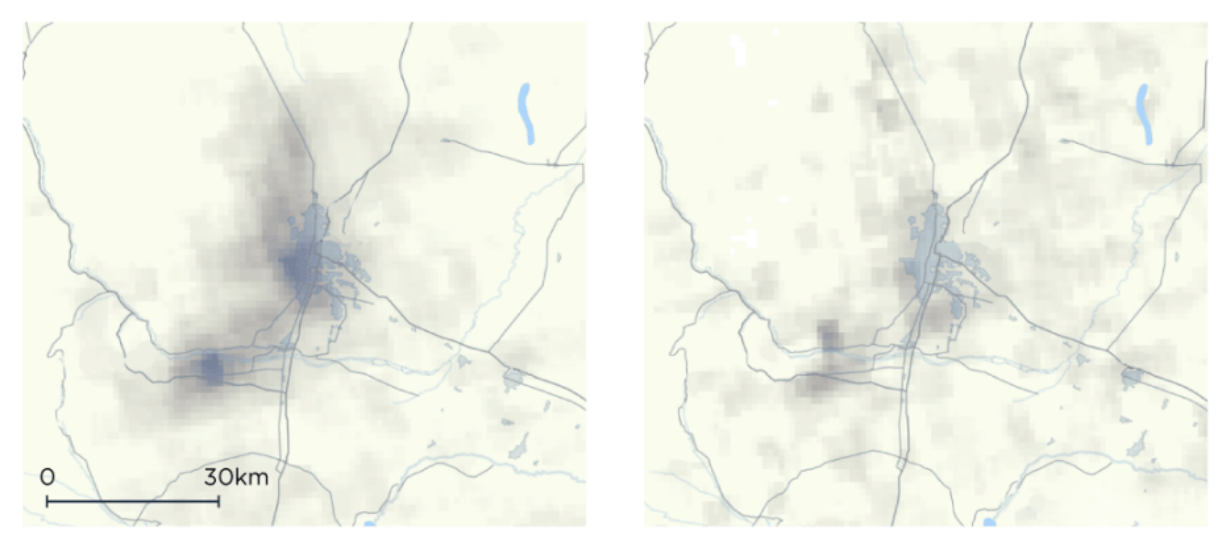

\section{Tucumán}
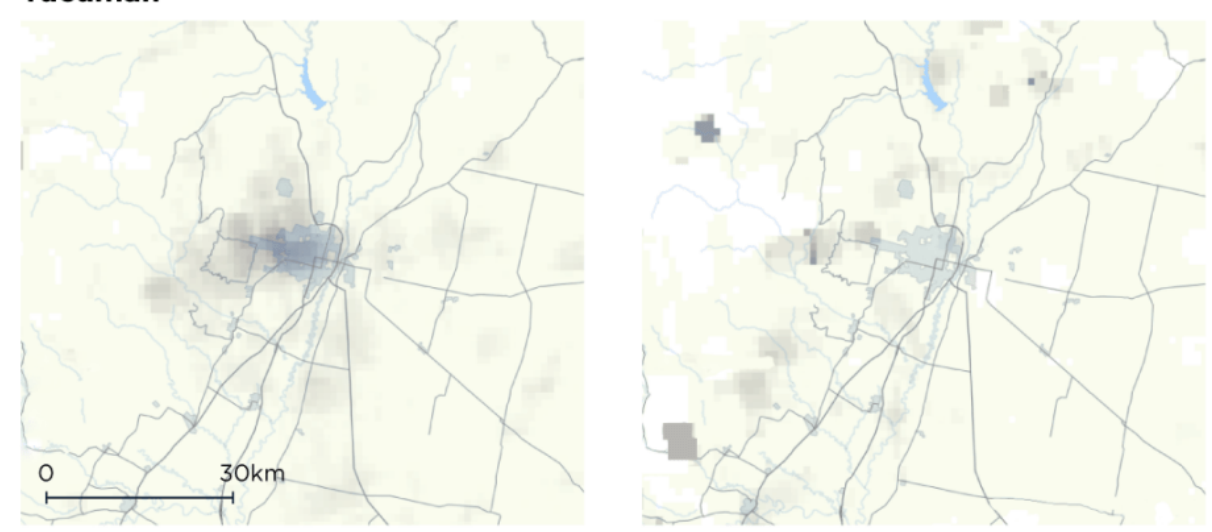

$\leq 10$

17,5

25

32,5

40

$\mathrm{NO}_{2}\left(\mu \mathrm{mol} / \mathrm{m}^{3}\right)$ 
Mapas elaborados por la CONAE en base a los datos del satélite Copérnico Sentinel-5P de la Agencia Espacial Europea, antes y después de la entrada en vigencia del Aislamiento Social, Preventivo y Obligatorio (ASPO) a partir de las 00.00h del 20 de marzo de 2020.

Estas imágenes muestran los valores promedio del NO2 en la atmósfera de las distintas ciudades, considerando datos correspondientes a las tres semanas previas de la entrada en vigencia del ASPO y las tres posteriores al anuncio del mismo. Siguiendo la tendencia de la mayoría de las grandes ciudades alrededor del mundo, se observa una clara disminución en los niveles de NO2 luego de la entrada en cuarentena. Esto se debe principalmente a una importante disminución en la movilidad, como se pudo comprobar a partir del análisis de datos (anónimos) del uso de aplicaciones móviles y Google Maps.

Por las importantes fluctuaciones que tienen los niveles de NO2 en condiciones normales en áreas urbanas, y algunas limitaciones de la tecnología satelital que se usa para medir sus niveles (por la influencia de las condiciones climáticas, como vientos, nubes y lluvias) es fundamental acompañar estas observaciones con mediciones en el terreno. Por ejemplo, en distintos medios de comunicación circuló que la contaminación atmosférica en la Ciudad de Buenos

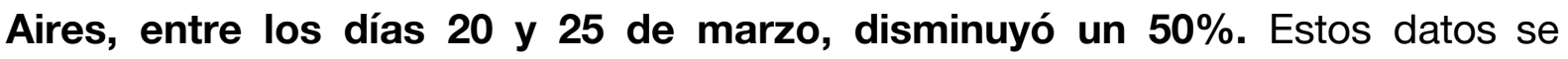
obtuvieron de estaciones de monitoreo localizadas en distintos puntos de la ciudad por técnicas que, en principio, son más confiables y tienen menos limitaciones, dado que utilizan métodos químicos de detección directa del NO2 en vez de estimaciones por datos satelitales. Pero (siempre hay un pero), el período analizado para llegar a esta conclusión incluyó principalmente un fin de semana largo (naturalmente con menor movimiento y, por lo tanto, menores emisiones), y los valores obtenidos han sido comparados con el valor promedio de marzo de 2019 (es decir, todos los datos metidos en la misma bolsa: horas del dia, semana, fin de semana).

En este caso, la impaciencia por publicar la información sacrifica la confianza y el jugo que se le puede sacar. Esa desmentida fácil es tierra fértil para quienes buscan la justificación perfecta para evitar hacer algo al respecto. Un mecanismo sutil de la posverdad que, sin embargo, no deja de inducirnos a conclusiones apresuradas, poco robustas, y hasta subestimadas. Porque usando más datos (más días) y comparándolos de alguna forma un poco más elaborada, llegamos a una conclusión similar ("la contaminación del aire de la ciudad disminuye 
durante la cuarentena") pero con un grado de certeza mucho mayor. Esta puesta en valor de la información y disponibilidad de evidencia de la mejor calidad posible es, en definitiva, lo que nos permitirá entender el camino que debemos tomar, decidir mejor, ser más libres.

El procesamiento y análisis de este tipo de información no es sencillo y además demora, si lo queremos hacer adecuadamente. Conforme pasa el tiempo, nuevos datos nos permiten entender más claramente la situación. De hecho, la disminución de los niveles de NO2 parecería ser incluso mayor a lo calculado inicialmente, confirmando lo que ya sospechábamos: la calidad del aire está mejorando durante la cuarentena, quizá más de lo que arrojaron las primeras estimaciones, y esto va a tener un impacto beneficioso para la salud, que se suma a la disminución de las chances de contagio del coronavirus por el aislamiento.

\section{Así no}

Una de las principales consecuencias de la contaminación ambiental es el calentamiento global por la emisión de gases de efecto invernadero, o GEI. Los GEI contribuyen al aumento de la temperatura de la Tierra y representan un aspecto central del cambio climático que estamos experimentando desde hace décadas. Son principalmente el dióxido de carbono, metano, óxido nitroso, y gases fluorados, ya que tienen la característica particular de dejar pasar la luz solar pero interfieren en la salida del calor, como el techo vidriado de un invernadero.

Algo muy llamativo es la forma en que los datos satelitales de más arriba fueron utilizados por analistas del sector agropecuario (como acá, acá y acá) para arrojar nuevos aspectos sobre la contribución de la ganadería en el calentamiento global. Notando que los niveles de NO2 han disminuido durante la cuarentena por la disminución del transporte y la actividad industrial, y siendo que no hay riesgo comprobado de que las vacas puedan contraer este virus por lo que pueden seguir tranquilas haciendo sus cosas de vacas, las primeras conclusiones fueron que la ganadería no contribuye significativamente con las emisiones de NO2 y, por lo tanto, con el calentamiento global. Más allá de que la lógica de este argumento pueda ser algo cuestionable, de lo que no hay lugar a dudas es de que el NO2 no es un Gas de Efecto Invernadero. Es un contaminante proveniente del transporte y la industria que afecta la salud de la de las personas que lo respiran, principalmente en ambientes urbanos, pero no contribuye significativamente al 
calentamiento global. Probablemente preste para confusión con el óxido nitroso (N2O) que, además de haber sido usado en grandes cantidades para un poco más de potencia en las primeras de Rápido y Furioso (las mejores), sí es un GEI, pero no es el que se midió en estas imágenes satelitales. A pesar de una amarga fe de erratas que se queda a mitad de camino, y como haciéndose la desentendida de estos intentos de manipulación de los datos, la ganadería sigue aportando un 10\% de las emisiones globales de GEl, y es el mayor contribuyente en nuestro país, con un $20,7 \%$.

\section{Lo bueno viene en frasco chico, pero el veneno también}

Volviendo a la relación entre respirar aire contaminado y la salud de las personas, la exposición a la contaminación ambiental produce y agrava enfermedades respiratorias, eso seguro. De hecho, probablemente aumente el riesgo de muerte en los pacientes que se infectan con el coronavirus actual (denominado SARS-Cov-2), como ya se observó en el brote de SARS causado por su primo (el SARS-Cov-1) en el 2003. Sin embargo, hay otros contaminantes en el aire, tanto o más relevantes que el NO2 respecto de sus efectos sobre la salud. De las 8,8 millones (imillones!) de muertes asociadas a la exposición a contaminación ambiental que ocurren todos los años en el mundo, la gran mayoría se produce por enfermedades cardiovasculares causadas por respirar partículas de contaminación ambiental, conocidas como partículas finas (PM2.5). Estas son totalmente invisibles al ojo humano, apenas más grandes que los virus, y hacen un despelote bárbaro en casi todo el cuerpo cuando las inhalamos. De hecho recientemente se ha demostrado que, en Estados Unidos, haber respirado altos niveles de estas partículas durante años aumenta el riesgo de muerte por COVID-19. Por esta razón, algunos consideran que la contaminación del aire debería ser considerada un factor de riesgo adicional para entender la alta letalidad del SARS-Cov-2 en zonas donde la calidad del aire es muy mala y este virus hizo estragos, como en el norte de Italia.

La permanencia de las partículas finas en la atmósfera es mayor que la del NO2, lo que hace que la variación en sus niveles -producida por cualquier mínimo cambio (como el inicio de una cuarentena mundial para frenar una pandemia, pongamos)- tarde más tiempo en verse reflejada. Además, su medición requiere de bastante más esfuerzo y validación, que hasta le escapa (al menos por el momento) a las garras de la posverdad. Quizá también le escapa por el pequeño detalle de que, a pesar de que es el componente tóxico más relevante del aire que respiramos, las estaciones de monitoreo de la Ciudad de Buenos Aires no 
miden partículas finas. Lo que se mide actualmente son partículas más grandes (conocidas como PM10) dado que es metodológicamente más sencillo, aunque brindan mucho menos información desde el punto de vista de los efectos perjudiciales de la contaminación ambiental sobre la salud. Además, la Ciudad de Buenos Aires cuenta con sólo 3 estaciones de monitoreo funcionando actualmente. Esto es muy poco teniendo en cuenta una población de 3 millones de personas, más los millones que ingresan todos los días a trabajar. De esta manera, estamos en condiciones de poder confirmar algunas de las observaciones satelitales, pero contamos con una cantidad de información muy limitada como para calcular los Índices de Calidad de Aire (AQI) que deberían utilizar las autoridades locales para elaborar recomendaciones para la población (por ejemplo, evitar salir cuando la calidad del aire afuera es muy mala) y tomar decisiones adecuadas.

Por estas razones todavía no tenemos (ni vamos a tener en el corto plazo) datos disponibles de estas partículas. Lo que sí sabemos es que las fuentes de emisión de las partículas finas y el NO2 son mayormente las mismas: el transporte y la industria. Por eso, si bajaron las emisiones de NO2 durante la cuarentena, es muy posible que pase lo mismo con estas partículas, con el consecuente beneficio sobre la salud que ello implica.

\section{Conocer el pasado para comprender el presente y decidir mejor en el futuro}

La mala es que vamos a tener que esperar para tener datos definitorios. La buena es que algunos eventos que han ocurrido en los últimos años nos pueden ayudar a imaginar cuál puede llegar a ser el alcance de la mejora de la calidad del aire por la cuarentena.

En el 2008, se celebraron los Juegos Olímpicos en la ciudad de Beijing. Durante todo ese año, el Gobierno Chino se propuso disminuir la contaminación ambiental mediante el cierre momentáneo de fábricas y restricciones en el uso de vehículos. En consecuencia, la calidad del aire mejoró entre un $18 \%$ y un $30 \%$, a lo que le siguió una disminución en algunos factores de riesgo de enfermedad cardiovascular. Lamentablemente, como tomar un antiinflamatorio para un dolor de muela, este efecto no duró demasiado. En cuanto la ciudad volvió a la actividad normal, el aire se hizo tan tóxico como antes de los Juegos Olímpicos. Sin embargo, a partir de los datos obtenidos en este 'experimento natural', se estimó que estas mejoras en la calidad del aire pueden evitar algo así como unas 
200.000 muertes. Sí, 200.000, sólo en China, sólo en un año. Además, el costo asociado a tamaña reducción de la mortalidad se calculó en ahorrar unos 50 mil millones de dólares. Lejos de tener o no sentido, muchas políticas públicas jamás llegan a ver la luz porque, simplemente, sus beneficios no son tan evidentes (o no se quieren ver) en el corto plazo.

En el contexto actual de pandemia y cuarentena, recientes estimaciones sugieren que la reducción de la contaminación ambiental previno unas 11.000 muertes en Europa, solo durante el mes de marzo. La principal causa parecería ser, justamente, una disminución en los niveles de NO2 y partículas finas por la disminución de la movilidad y el menor uso de carbón para la obtención de energía eléctrica.

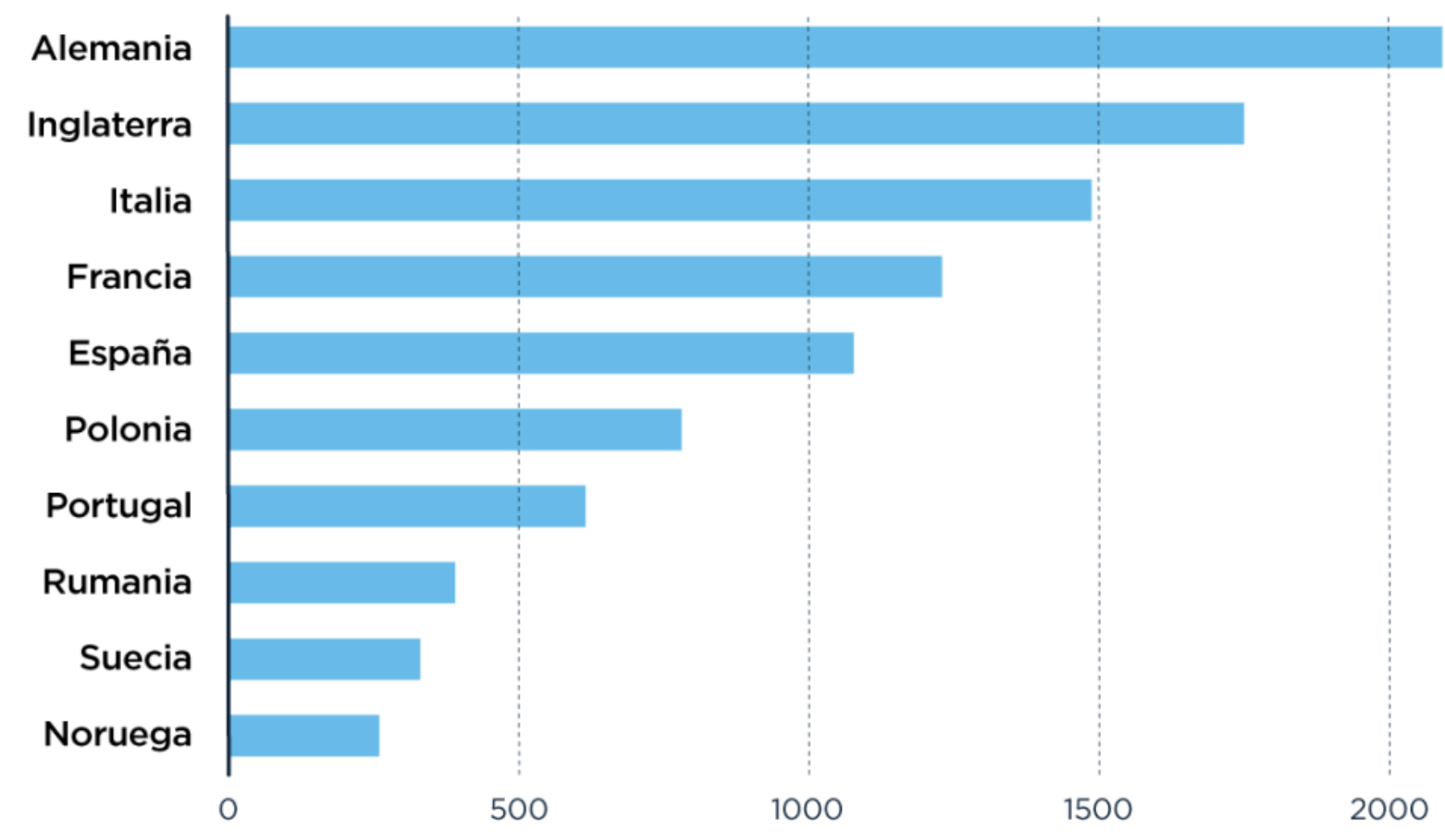

Muertes evitadas

Estimaciones del número de muertes que se han evitado durante el mes de marzo de 2020 por la reducción de la contaminación ambiental (relacionada a la entrada en cuarentena de distintos países para frenar el avance del COVID-19). Fuente: CREA. 
Esta situación nos muestra (nuevamente) que, aunque todavía muchos no estén del todo convencidos, la contaminación ambiental verdaderamente existe y es altamente perjudicial para la salud. Como si fuera poco, este suceso confirma que la disminución de la calidad del aire se encuentra directamente asociada con el desarrollo de las actividades del hombre, cuando se hacen de una forma poco amigable con el medioambiente. Pero por sobre todo ( $y$ acá es donde nos ponemos optimistas), todo esto demuestra que es absolutamente posible hacer algo al respecto.

China es un gigante de casi 1.400 millones de personas, donde tanto los niveles de contaminación como los efectos de su reducción son difícilmente comparables con casi cualquier otro lugar del mundo. Pero estas 'intervenciones' momentáneas nos sirven para generar la evidencia necesaria para promover un verdadero cambio de fondo. Uno que va a ocurrir cuando tomemos medidas definitivas, no transitorias. Cuando terminemos de entender que es fundamental mejorar el manejo de la información y la comunicación de la misma, y que debemos enfocar nuestros esfuerzos hacia un cambio de paradigma en los modelos de consumo, donde la evidencia científica disponible indica claramente que el actual no es un formato que pueda ser sostenible por mucho más tiempo. Por ejemplo, en los años '90, Dublín tenía un serio problema con la contaminación de su aire, por lo que se prohibió el uso del carbón de hulla para la obtención de energía y la calefacción de los hogares. Esto redujo las emisiones de material particulado en un $70 \%$, lo que condujo a una disminución de las muertes por enfermedades respiratorias del $15,5 \%$ y cardiovasculares en un 10,3\%, es decir, unas 350 muertes menos por año desde de la entrada en vigencia de la prohibición, sólo en Irlanda. Algo similar ocurrió en Hong Kong, cuando se prohibió el uso de combustibles con alto contenido de azufre. Este tipo de acciones y recomendaciones que han funcionado en otros lugares pueden ser actualizadas y adaptadas a nuestra realidad, aunque sin la voluntad política de impulsarlas ( $\mathrm{y}$ de una comunidad que las reclame) difícilmente progresen.

\section{Cuarentena y desigualdades}

¿Es momento de preocuparnos por la calidad del aire justo ahora, con una pandemia en curso y una economía que ya estaba en terapia intensiva y ahora va a tardar mucho más en recuperarse? ¿En un contexto en el cual la acción y la toma rápida de decisiones es vital, tiene sentido preocuparnos por beneficios que (teóricamente) sólo veremos en el largo plazo? 
Por un lado, no necesariamente deberíamos plantearnos esto como un dilema en el que nos toca elegir entre contaminar menos o salir de la crisis económica. Seguramente se pueda encontrar un equilibrio viable en algún lugar en el medio. Por el otro, siempre es un buen momento para tratar de entender un poco mejor las desigualdades de las personas y repensar estrategias para hacer algo al respecto. De repente caemos en la cuenta de que tenemos un sistema de salud altamente propenso a saturarse, un sistema científico desfinanciado, un sistema educativo desactualizado. Pilares del desarrollo de las sociedades que en este momento se mantienen más por la calidad y el esfuerzo del capital humano que por la infraestructura y los insumos con los que cuentan. En general, mientras las crisis exponen estas fragilidades en los modelos, las personas de menores recursos son quienes se llevan la peor parte. Y esta no es la excepción.

La disminución del contacto social y el aislamiento han sido fundamentales para frenar la propagación del virus, y parecería que lo estamos haciendo bastante bien. Sin embargo, mientras que disminuir la movilidad le es por lo menos incómodo a la mayoría, para los sectores más pobres es mucho más complicado, casi un lujo. Además, para sorpresa de nadie, este contexto ha hecho que también las desigualdades de género salieran a la luz, aunque para discutirlas adecuadamente requerirían una nota entera aparte (como esta o esta). La cuestión es que, visto a gran escala, mientras que los sectores más ricos cuentan con más herramientas para hacerle frente a esta pandemia, los sectores de menores ingresos son los más afectados. Algo similar ocurre con los grupos que más contaminan (el 10\% más rico) respecto de los que más sufren sus consecuencias (el $50 \%$ más pobre), al punto de que un bajo nivel socioeconómico es considerado como un factor de riesgo adicional para los efectos perjudiciales de respirar aire de mala calidad. Dirigir esfuerzos y recursos en contaminar menos es, también, tratar de equilibrar desigualdades sociales.

Pero las crisis son oportunidades. Primero lo primero, pasemos esta. Se han hecho grandes esfuerzos y sacrificios para frenar la expansión de este virus que tiene en vilo al mundo desde principios de año. $Y$ no es para menos. Tampoco es momento de aflojar. Simplemente, no estaría nada mal sacarle el mayor provecho posible a toda esta situación. Desde que comenzó la cuarentena se limpió el aire de la mayoría de las grandes ciudades alrededor del mundo. Y no, no hay delfines en los canales de Venecia, pero tampoco hace falta tanto. Cuando esto termine y retomemos nuestras vidas, si prestamos atención, vamos a ver que el ambiente recuperó algunas posiciones. Un buen momento para reflexionar sobre nuestros comportamientos y decidir qué actitud podríamos tomar (individualmente, como 
comunidad, como pueblo, como especie) para preservarlo, en nuestro propio beneficio. Puede ser una actitud negacionista, una pasiva, o la que va a cambiar al mundo.

\section{About the author:}

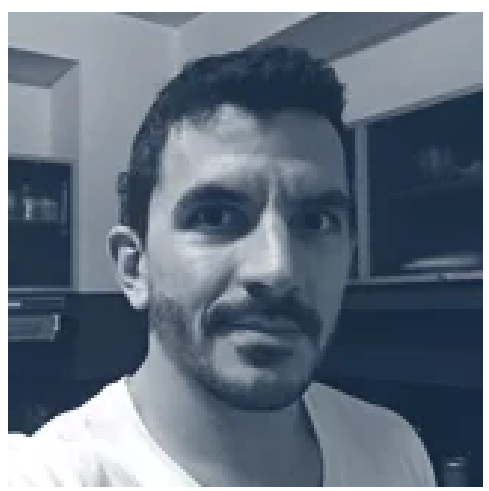

Chemistry professor. Researcher in environmental pollution. Irrecoverable detailist. I don't have a middle name, the first one was more than enough. 